\title{
Raltegravir 1200 mg Once Daily vs 400 mg Twice Daily, With Emtricitabine and Tenofovir Disoproxil Fumarate, for Previously Untreated HIV-1 Infection: Week 96 Results From ONCEMRK, a Randomized, Double-Blind, Noninferiority Trial
}

\author{
Pedro Cahn, MD,* Paul E. Sax, MD, † Kathleen Squires, MD, $\neq$ Sean-Michel Molina, MD,\| \\ Winai Ratanasuwan, MD, 9 Mohammed Rassool, MD,\# Mark Bloch, MD, ${ }^{* *}$ Xia Xu, PhD, $\dagger$ \\ Yan Zhou, PhD, $\dagger+$ Brenda Homony, MS, $\dagger+$ Deborah Hepler, BSMT, $\dagger \dagger$ Hedy Teppler, MD, $\dagger+$ \\ George J. Hanna, MD, †† Bach-Yen Nguyen, MD, †† and Wayne Greaves, MD, $\dagger$ † \\ for the ONCEMRK Study Group
}

Background: Raltegravir $1200 \mathrm{mg}(2 \times 600 \mathrm{mg}$ tablets) once daily (QD) demonstrated noninferior efficacy and similar safety to raltegravir 400mg twice daily (BID) at week 48 of the ONCEMRK trial. Here, we report the week 96 results from this study.

Methods: ONCEMRK is a phase 3, multicenter, double-blind, noninferiority trial comparing raltegravir $1200 \mathrm{mg}$ QD with raltegravir $400 \mathrm{mg}$ BID in treatment-naive HIV-1-infected adults. Participants were assigned $(2: 1)$ to raltegravir $2 \times 600 \mathrm{mg}$ QD or $400 \mathrm{mg}$ BID, both with emtricitabine and tenofovir disoproxil fumarate (FTC/TDF) for 96 weeks. Randomization was stratified by screening HIV-1 RNA and hepatitis B/C status. Efficacy was assessed as the proportion of participants with HIV-1 RNA $<40$ copies per milliliter (Food and Drug Administration Snapshot approach); the noninferiority margin was 10 percentage points.
Results: Of the 797 participants who received study therapy $(84.6 \%$ were men, $59.3 \%$ were white, and mean age was 35.9 years), 694 completed 96 weeks of treatment (87.6\% QD; 84.4\% BID), with few discontinuations because of lack of efficacy ( $1.1 \%$ for both groups) or adverse events (1.3\% QD; 2.3\% BID). At week 96, 81.5\% (433/ $531)$ of QD recipients and $80.1 \%(213 / 266)$ of BID recipients achieved HIV-1 RNA $<40$ copies per milliliter (difference $1.4 \%$, 95\% confidence interval: -4.4 to 7.3 ). $\mathrm{CD}^{+} \mathrm{T}$-cell counts increased $>260$ cells $/ \mathrm{mm}^{3}$ from baseline in both groups. Resistance to raltegravir was infrequent, occurring in $0.8 \%$ of each treatment group through week 96 . Adverse event rates were similar for the 2 regimens.

Conclusions: In HIV-1-infected treatment-naive adults receiving FTC/TDF, raltegravir 1200mg QD demonstrated noninferior efficacy

Received for publication December 31, 2017; accepted April 16, 2018.

From the *Fundación Huesped, Buenos Aires, Argentina; †Brigham and Women’s Hospital, Harvard Medical School, Boston, MA; $\ddagger$ Thomas Jefferson University, Philadelphia, PA; §Currently, Merck \& Co., Inc., Kenilworth,Rahway, NJ; \|Hôpital Saint-Louis, University of Paris Diderot, Paris, France; $\{$ Faculty of Medicine Siriraj Hospital, Clinical HIV Research Unit, Mahidol University, Bangkok, Thailand; \#University of Witwatersrand, Helen Joseph Hospital, Johannesburg, South Africa; **Holdsworth House Medical Practice, Sydney, Australia; and ††Merck \& Co., Inc., Kenilworth, NJ.

Supported by Merck \& Co., Inc., Kenilworth, NJ.

Presented in part at the 9th IAS Conference on HIV Science;July 23-26, 2017; Paris, France, and the 16th European AIDS Conference;October 25-27, 2017; Milan, Italy.

P.C. is an advisory board member of Merck and ViiV and received research grant support from AbbVie, Merck, and ViiV. P.S. serves as a consultant to or scientific advisory board member of AbbVie, BMS, Gilead, GSK/ViiV, Merck, and Janssen and received research grant support from Bristol Myers Squibb, Gilead, Merck, and GSK/ViiV. K.S. is an advisory board member of Bristol Myers Squibb, Gilead Sciences, Janssen, Merck, and ViiV and received research grant support from Gilead. J.-M.M. is an advisory board member of Merck, Gilead, Bristol Myers Squibb, ViiV, Janssen, and Teva. M.B. received research grants, is an advisory board member, meeting presentations for Amgen, Merck, Gilead Sciences, ViiV Healthcare, and AbbVie. K.S., X.X., Y.Z., B.H., D.H., H.T., G.H., B.-Y.N., and W.G. are current or former employees of Merck Sharp \& Dohme Corp., a subsidiary of Merck \& Co., Inc., Kenilworth, NJ, and may own stock and/or stock options. The remaining authors have no conflicts of interest to disclose.

Registration: ClinicalTrials.govNCT02131233.

Members of the ONCEMRK Study Group are listed in Appendix 1.

Supplemental digital content is available for this article. Direct URL citations appear in the printed text and are provided in the HTML and PDF versions of this article on the journal's Web site (www.jaids.com).

Correspondence to: Wayne Greaves, MD, Merck \& Co., Inc., 126 E. Lincoln Avenue, RY34-A484, Rahway, NJ 07065-0900(e-mail: wayne.greaves@merck. com).

Copyright (C 2018 The Author(s). Published by Wolters Kluwer Health, Inc. This is an open-access article distributed under the terms of the Creative Commons Attribution-Non Commercial-No Derivatives License 4.0 (CCBY-NC-ND), where it is permissible to download and share the work provided it is properly cited. The work cannot be changed in any way or used commercially without permission from the journal. 
to raltegravir 400mg BID that was durable to week 96 , with a safety profile similar to raltegravir $400 \mathrm{mg}$ BID.

Key Words: raltegravir, once daily, integrase inhibitor, HIV-1 infection, treatment-naive

(J Acquir Immune Defic Syndr 2018;78:589-598)

\section{INTRODUCTION}

Raltegravir $400 \mathrm{mg}$ twice daily (BID), the first integrase strand transfer inhibitor (INSTI) approved for the treatment of HIV-1 infection, has a well-established safety and efficacy profile in treatment-naive and treatment-experienced patients. $^{1-4}$ A once-daily formulation of raltegravir $1200 \mathrm{mg}$ $(2 \times 600 \mathrm{mg}$ tablets $)$ has been developed and has the potential to improve treatment adherence and satisfy patient preference for a once-daily regimen. ${ }^{5-8}$ This new formulation is approved for use in combination with other antiretroviral agents for previously untreated HIV-1 infection in adults and in children weighing $\geq 40 \mathrm{~kg} .{ }^{9}$ In the ONCEMRK phase 3 trial, raltegravir $1200 \mathrm{mg}$ once daily (QD) showed noninferior efficacy to raltegravir $400 \mathrm{mg}$ BID, with $88.9 \%$ and $88.3 \%$ of participants, respectively, achieving HIV-1 RNA $<40$ copies per milliliter at week $48 .{ }^{10}$ In addition, the immunologic efficacy and overall safety profile of raltegravir QD were similar to those of raltegravir BID at week 48. Here, we report the long-term efficacy and safety of raltegravir $1200 \mathrm{mg}$ QD compared with raltegravir $400 \mathrm{mg}$ BID through week 96 of the ONCEMRK trial.

\section{METHODS}

\section{Study Design}

ONCEMRK (MK-0518 Protocol 292; ClinicalTrials. gov NCT02131233) was a double-blind, randomized, parallel group, noninferiority study comparing raltegravir $1200 \mathrm{mg}$ QD with raltegravir $400 \mathrm{mg}$ BID, each given with a fixed combination of emtricitabine $200 \mathrm{mg}$ and tenofovir disoproxil fumarate $300 \mathrm{mg}$ (FTC/TDF). The study was conducted according to Good Clinical Practice requirements and applicable statutes and regulations regarding the protection of human participants in biomedical research. An Independent Ethics Committee for each study site reviewed and approved the protocol, and the participants provided written informed consent before any study procedures were performed.

Adults ( $\geq 18$ years of age) with screening HIV-1 RNA $\geq 1000$ copies per milliliter and no previous antiretroviral therapy for treatment of HIV-1 infection were eligible for the study. Exclusion criteria included documented or known resistance to any of the study regimen components and acute hepatitis or active infections other than chronic hepatitis B or $\mathrm{C}$ infection. Participants were randomly assigned $(2: 1)$ to raltegravir $1200 \mathrm{mg}$ QD or $400 \mathrm{mg}$ BID, each in combination with open-label FTC/TDF (TRUVADA; Gilead Sciences, Inc., Carrigtohill, County Cork, Ireland) for up to 96 weeks. Randomization was stratified by screening HIV-1 RNA ( $\leq 100,000$ or $>100,000$ copies per milliliter) and hepatitis $\mathrm{B} / \mathrm{C}$ coinfection (yes or no). To conceal the treatment group assignment, participants also received placebo tablets matching the alternate treatment. Participants, study site investigators and staff, and sponsor personnel responsible for monitoring the study remained unaware of the treatment group assignments until the week 96 database lock.

\section{Procedures}

Plasma HIV-1 RNA levels were measured by the central laboratory using the Abbott RealTime HIV-1 Assay (lower limit of quantification 40 copies per milliliter). Protocol-defined virologic failure (PDVF) was used to identify participants for viral resistance testing. PDVF consisted of nonresponse (participant did not achieve HIV-1 RNA $<40$ copies per milliliter by week 24 ) or rebound (after initial response of HIV-1 RNA $<40$ copies per millliliter, participant had 2 consecutive measurements of HIV-1 RNA $\geq 40$ copies per milliliter at least 1 week apart). Resistance testing was performed by Monogram Biosciences Inc. using the following assays: PhenoSense GT, PhenoSense Integrase, and either GeneSeq Integrase or GenoSure Integrase; all assays required samples with HIV-1 RNA $\geq 500$ copies per milliliter.

$\mathrm{CD}^{+} \mathrm{T}$-cell counts were measured at weeks $24,48,72$, and 96 by the central laboratory according to standard procedures. All clinical adverse events were evaluated for maximum intensity, seriousness, relationship to test drugs, and association with immune reconstitution syndrome. All protocol-required laboratory values were graded according to the Division of AIDS criteria. ${ }^{11}$

Participants completed a daily medication diary that was reviewed by site personnel at each study visit. A day within the study was counted as "on therapy" if at least 1 tablet of any study medication was taken. Treatment compliance was calculated from the number of days on therapy as recorded in the medication diary (actual/planned $\times 100$ ). For participants who were compliant with therapy but had HIV-1 RNA > 200 copies per milliliter (on 2 consecutive measurements taken at least 1 week apart) on or after week 24 or after previously achieving HIV-1 RNA $<40$ copies per milliliter, the protocol recommended that discontinuation of study therapy should be considered by the study investigator.

\section{Statistical Analysis}

The primary efficacy end point for this trial was assessed at week 48 and has been previously reported. ${ }^{10}$ This report presents additional data to evaluate the secondary hypothesis that raltegravir $1200 \mathrm{mg}$ QD is noninferior to raltegravir $400 \mathrm{mg} \mathrm{BID}$, each in combination with TDF/FTC, as assessed by the proportion of participants achieving HIV-1 RNA $<40$ copies per milliliter at week 96 . A margin of 10 percentage points was used to assess noninferiority. The week 96 hypothesis was tested sequentially after the week 48 hypothesis was successfully met; therefore, the overall type I error was controlled at one-sided $2.5 \%$ alpha level.

The efficacy analyses used the Full Analysis Set population, defined as all randomized participants who received at least 1 dose of study treatment, with participants 
included in the treatment group to which they were randomized. SAS version 9.3 or 9.4 was used for all analyses.

For the analysis of the proportion of participants with HIV-1 RNA $<40$ copies per milliliter, all missing data were treated as failures regardless of the reason, including early discontinuation of study therapy (Food and Drug Administration snapshot approach). The difference in proportions between treatment groups and the associated $95 \%$ confidence

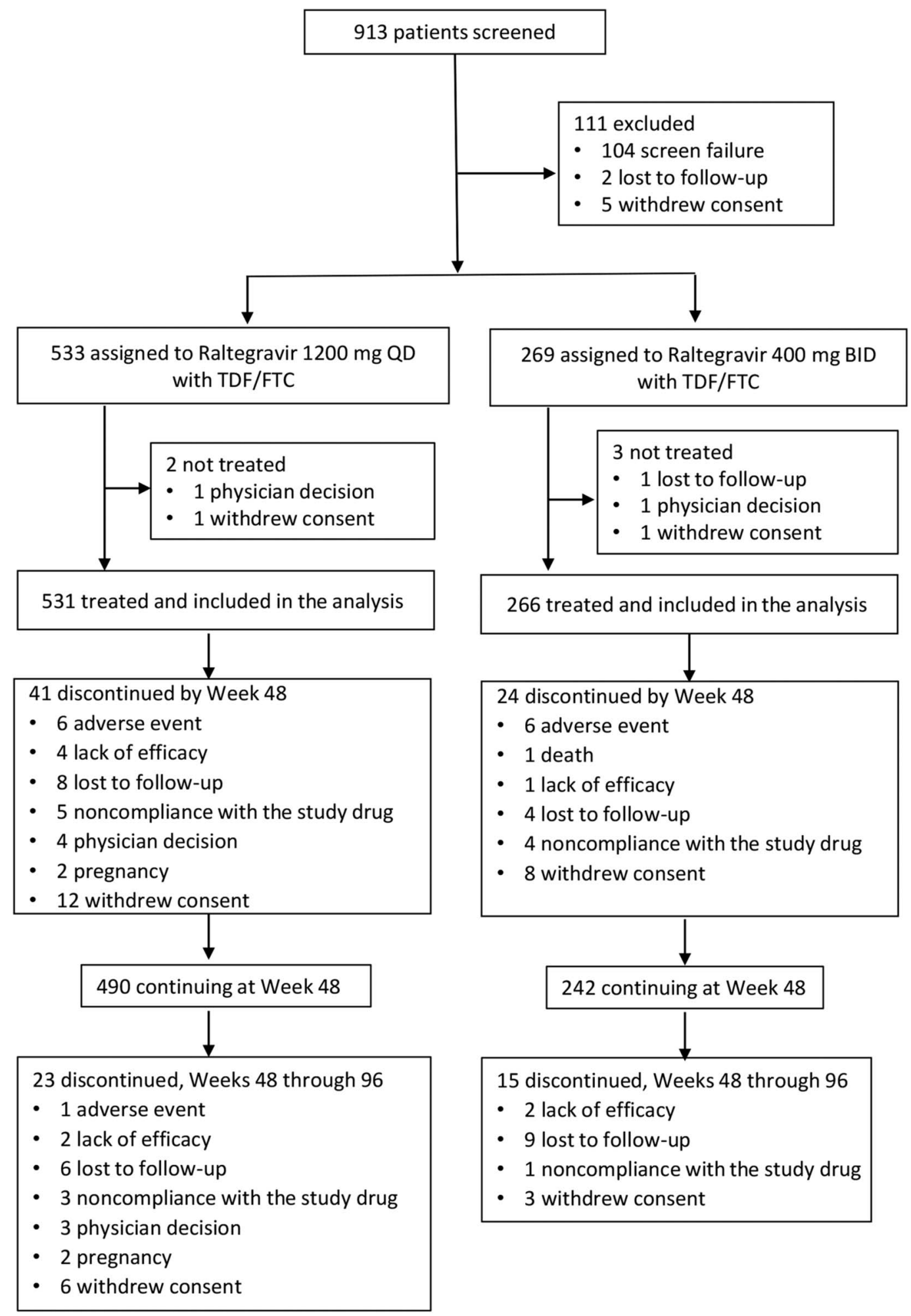

FIGURE 1. Disposition of study participants. 
FIGURE 2. Proportion of participants with HIV1 RNA $<40$ copies per milliliterover time, Food and Drug Administration snapshot approach. Raltegravir (RAL) $1200 \mathrm{mg}$ QD and $400 \mathrm{mg}$ BID were given with TDF/FTC.

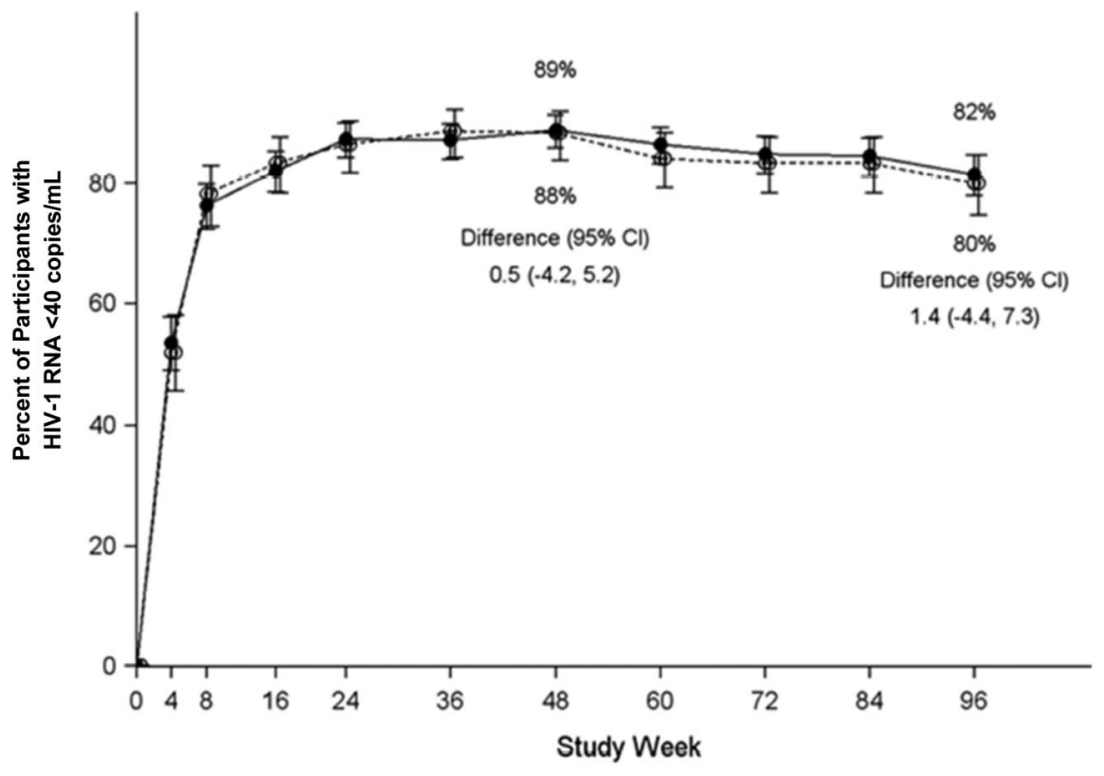

- Raltegravir $1200 \mathrm{mg}$ QD

- Raltegravir $400 \mathrm{mg}$ BID interval (CI) were calculated by the stratum-adjusted MantelHaenszel method. A supportive analysis of the proportion of participants with HIV-1 RNA $<50$ copies per milliliter was also performed using the methods described above.

For the analysis of change from baseline in $\mathrm{CD}^{+} \mathrm{T}$-cell counts, missing data were handled with the Observed Failure (OF) approach. Baseline values were carried forward for participants who discontinued the assigned therapy because of lack of efficacy and for those who discontinued for non-treatment-related reasons and had HIV-1 RNA $\geq 40$ copies per milliliter; participants with missing data for other reasons were excluded.

To evaluate the consistency of treatment effects, the virologic and immunologic end points were estimated within subgroups based on a variety of prognostic and demographic factors using the OF approach (see above); no hypothesis testing was performed within or between subgroups. The OF approach was used because it focuses on the impact of the antiretroviral treatment, whereas the snapshot approach considers the impact of treatment and non-treatment-related factors.

The safety analyses used the all-participants-as-treated population, which consists of all randomized participants who received at least 1 dose of study treatment and includes participants in the treatment group for the regimen they actually received. Adverse events that occurred after randomization and were reported through the week 96 window were included in the analyses. Adverse event terms from the Medical Dictionary for Regulatory Activities (Version 18.1) were used. For laboratory changes occurring in $\geq 1 \%$ of the participants in either treatment group, between-treatment differences (and 95\% CI) were calculated using the Miettinen and Nurminen method. ${ }^{12}$

\section{RESULTS}

Of the 802 randomized participants, 797 received study therapy and were included in the efficacy and safety analyses.
Baseline characteristics of the participants were similar between the treatment groups (see Table, Supplemental Digital Content 1, http://links.lww.com/QAI/B166). Mean age of the study population was 35.9 years, and $85 \%$ of the participants were men. Mean HIV-1 RNA was $4.6 \log _{10}$ copies per milliliter, and $28 \%$ of participants had $>100,000$

TABLE 1. Virologic Outcomes at Week 96

\begin{tabular}{|c|c|c|}
\hline & $\begin{array}{c}\text { Raltegravir } 1200 \mathrm{mg} \\
\text { QD (N=531) } \\
\end{array}$ & $\begin{array}{c}\text { Raltegravir } 400 \mathrm{mg} \\
\text { BID (N=266) } \\
\end{array}$ \\
\hline & n (\%) & n(\%) \\
\hline \multicolumn{3}{|l|}{ Primary endpoint $(\mathrm{NC}=\mathrm{F})$} \\
\hline HIV-1 RNA $<40$ copies/mL & $433(81.5)$ & $213(80.1)$ \\
\hline HIV-1 RNA $\geq 40$ copies/mL* & $49(9.2)$ & $22(8.3)$ \\
\hline $\begin{array}{l}\text { No virologic data at week } 96 \\
\text { window }\end{array}$ & $49(9.2)$ & $31(11.7)$ \\
\hline $\begin{array}{l}\text { Discontinued study } \\
\text { because of } \mathrm{AE} \text { or death }\end{array}$ & $7(1.3)$ & $7(2.6)$ \\
\hline $\begin{array}{l}\text { Discontinued study for } \\
\text { other reasons } \dagger\end{array}$ & $36(6.8)$ & $20(7.5)$ \\
\hline $\begin{array}{l}\text { On study therapy but } \\
\text { missing data in window }\end{array}$ & $6(1.1)$ & $4(1.5)$ \\
\hline \multicolumn{3}{|l|}{ Supportive endpoints } \\
\hline$<40$ copies/mL (OF) & 433/482 (89.8) & 213/235 (90.6) \\
\hline$<50$ copies/mL $(\mathrm{NC}=\mathrm{F})$ & 439/531 (82.7) & $215 / 266(80.8)$ \\
\hline$<50$ copies/mL (OF) & $439 / 482(91.1)$ & $215 / 235(91.5)$ \\
\hline \multicolumn{3}{|c|}{$\begin{array}{l}\text { Raltegravir } 1200 \mathrm{mg} \text { QD and } 400 \mathrm{mg} \text { BID were administered with FTC/TDF. } \\
\text { *Includes participants who changed any component of background therapy to a new } \\
\text { drug class, to components not permitted per protocol, or because of lack of efficacy } \\
\text { before week } 96 \text {; participants who discontinued before week } 96 \text { because of lack or loss of } \\
\text { efficacy; and participants with HIV-1 RNA } \geq 40 \text { copies per milliliter in the week } 96 \\
\text { window (relative day } 631-714 \text { ). } \\
\quad \text { †Other reasons include the following: lost to follow-up, noncompliance with the } \\
\text { study drug, physician decision, pregnancy, and withdrawal by the subject. } \\
\text { OF, Observed Failure approach; NC=F, Non-Completer equals Failure approach (as } \\
\text { defined by FDA snapshot algorithm). }\end{array}$} \\
\hline
\end{tabular}



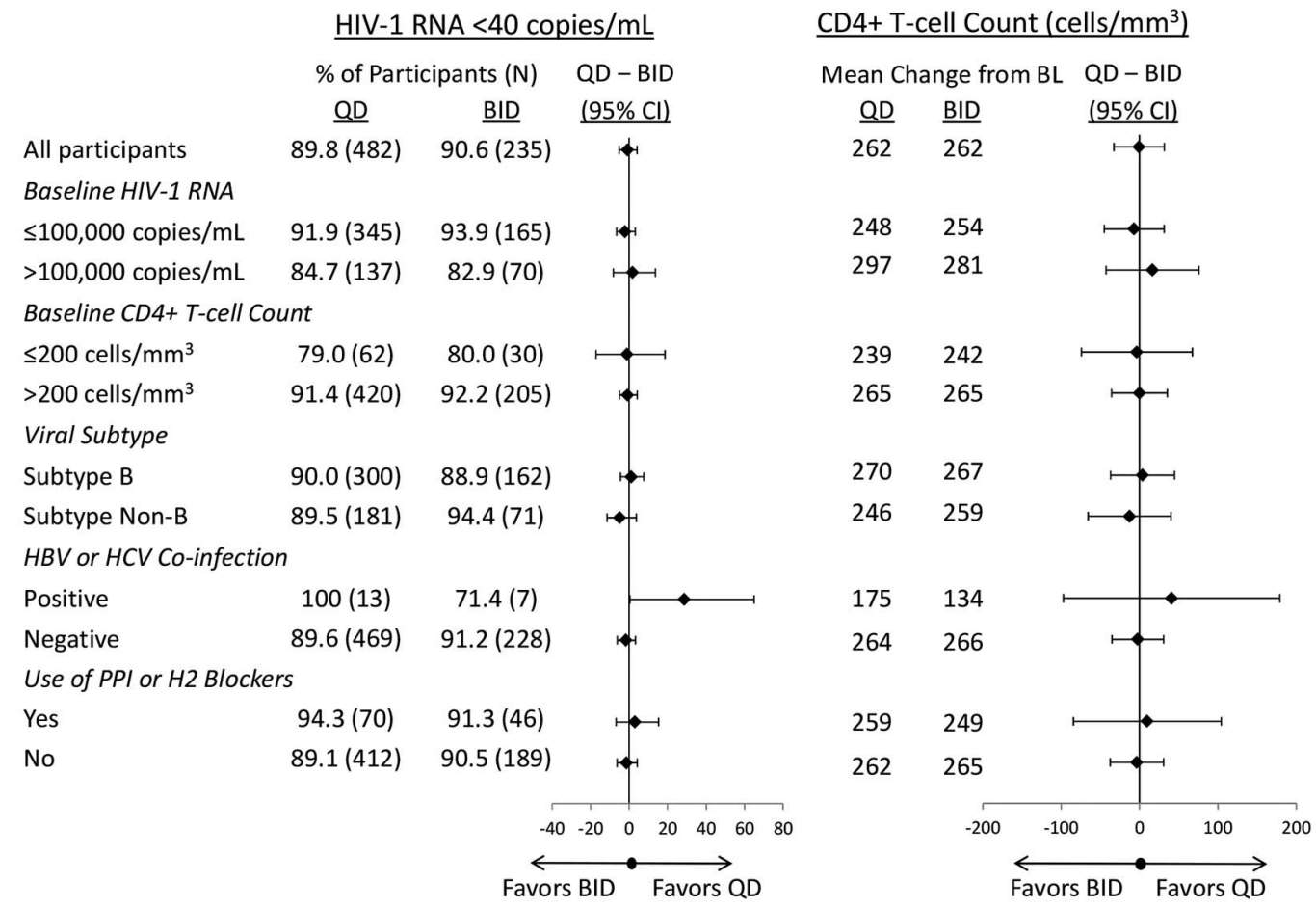

\begin{tabular}{|c|c|c|c|}
\hline & \multicolumn{3}{|c|}{ HIV-1 RNA <40 copies/mL } \\
\hline & \multicolumn{2}{|c|}{$\%$ of Participants (N) } & \multirow{2}{*}{$\begin{array}{l}Q D-B I D \\
(95 \% \mathrm{CI})\end{array}$} \\
\hline & $\underline{Q D}$ & $\underline{B I D}$ & \\
\hline All participants & $89.8(482)$ & $90.6(235)$ & \\
\hline \multicolumn{4}{|l|}{ Age } \\
\hline$\leq$ Median (34y) & $88.7(247)$ & $88.9(108)$ & 7 \\
\hline$>$ Median (34y) & $91.1(235)$ & $92.1(127)$ & 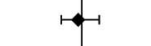 \\
\hline \multicolumn{4}{|l|}{ Sex } \\
\hline Male & $90.0(401)$ & $90.7(205)$ & 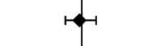 \\
\hline Female & $88.9(81)$ & $90.0(30)$ & $\longmapsto$ \\
\hline \multicolumn{4}{|l|}{ Race/Ethnicity } \\
\hline Asian & $93.8(80)$ & $97.3(37)$ & $\vdash$ \\
\hline Black & $78.2(87)$ & $78.6(28)$ & \\
\hline White & $91.9(270)$ & $92.2(153)$ & $\mapsto-1$ \\
\hline Hispanic/Latino & $95.7(115)$ & $88.6(44)$ & \\
\hline \multicolumn{4}{|l|}{ Region } \\
\hline Africa & 89.7 (39) & $83.3(12)$ & - \\
\hline Asia/Pacific & $93.9(82)$ & $97.4(38)$ & $\mapsto$ \\
\hline Europe & $90.0(180)$ & $92.4(105)$ & $\mapsto \bullet$ \\
\hline Latin America & $93.2(73)$ & $84.0(25)$ & \\
\hline \multirow[t]{2}{*}{ North America } & $84.3(108)$ & $87.3(55)$ & $\bullet$ \\
\hline & & -40 & $\begin{array}{ll}-20 & 0\end{array}$ \\
\hline
\end{tabular}

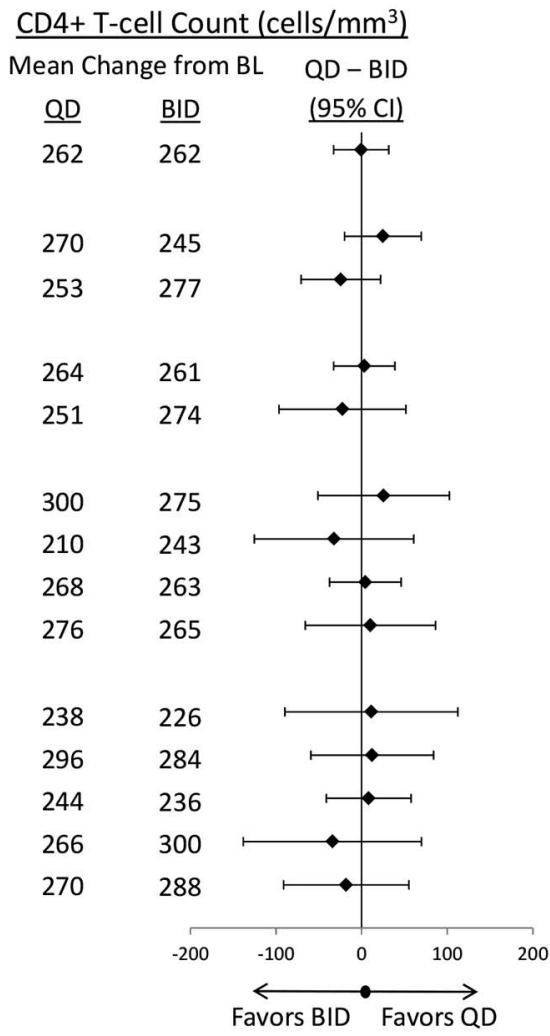

FIGURE 3. Efficacy of raltegravir $1200 \mathrm{mg}$ QD and raltegravir $400 \mathrm{mg}$ BID by baseline prognostic and demographic factors (Observed Failure approach).

copies per milliliter; mean CD4 ${ }^{+}$T-cell count was $415 / \mathrm{mm}^{3}$ and $13 \%$ had $<200 / \mathrm{mm}^{3}$. A total of 64 participants $(12.0 \%)$ from the raltegravir QD group and $39(14.5 \%)$ from the raltegravir BID group discontinued early without completing the study. The most common reasons for discontinuation were lost to follow-up and withdrawal by the subject (Fig.1). 
TABLE 2. Protocol-Defined Virologic Failure and Resistance Testing

\begin{tabular}{|c|c|c|}
\hline & $\begin{array}{l}\text { RAL } 1200 \text { mgQD + } \\
\text { TDF/FTC }(\mathbf{N}=531)\end{array}$ & $\begin{array}{c}\text { RAL } 400 \mathrm{mg} \text { BID } \\
+ \text { TDF/FTC } \\
(\mathrm{N}=266)\end{array}$ \\
\hline Participants with PDVF* & $51(9.6)$ & $26(9.8)$ \\
\hline Tested for resistance $\dagger$ & $17(3.2)$ & $8(3.0)$ \\
\hline $\begin{array}{l}\text { HIV-1 RNA (copies } / \mathrm{mL} \text { ) } \\
\text { of resistance sample, } \\
\text { median (range) }\end{array}$ & $2180(54-151,154)$ & $\begin{array}{c}1234(<40 \text { to } \\
228,213)\end{array}$ \\
\hline $\begin{array}{l}\text { Time (wk) between Failure } \\
\text { and resistance testing, } \\
\text { median (range) } \ddagger\end{array}$ & $12(0-70)$ & $7(0-57)$ \\
\hline \multicolumn{3}{|l|}{ Resistance test results } \\
\hline $\begin{array}{l}\text { No known RAL resistance } \\
\text { mutations }\end{array}$ & $9(1.7)$ & $3(1.1)$ \\
\hline $\begin{array}{c}\text { Failed integrase } \\
\text { amplification }\end{array}$ & $4(0.8)$ & $3(1.1)$ \\
\hline $\begin{array}{l}\text { RAL resistance mutations } \\
\text { detected }\end{array}$ & $4(0.8)$ & $2(0.8)$ \\
\hline \multirow[t]{3}{*}{$\begin{array}{l}\text { Resistance pattern } \\
\text { (INSTI and NRTI) }\end{array}$} & $\begin{array}{c}\text { 1: N155H, V151I; } \\
\text { M184V }\end{array}$ & $\begin{array}{r}\text { 1: T97A, I203M; } \\
\text { K65K/R, M184I }\end{array}$ \\
\hline & 2: N155H; M184M/I/V & $\begin{array}{c}\text { 2: N155H, I203M, } \\
\text { L74I; D67D/N, } \\
\text { M184V }\end{array}$ \\
\hline & $\begin{array}{c}\text { 3: L47M, E92Q; M184V } \\
\text { 4: N155H, I203M; } \\
\text { M184V }\end{array}$ & \\
\hline $\begin{array}{l}\text { Time (wk) between } \\
\text { Failure and resistance } \\
\text { testing, median (range) }\end{array}$ & $12(0-28)$ & $30(3-57)$ \\
\hline \multicolumn{3}{|l|}{$\begin{array}{l}\text { Resistance by baseline } \\
\text { factors }\end{array}$} \\
\hline \multicolumn{3}{|l|}{ HIV-1 RNA (copies/mL) } \\
\hline$<100,000$ & $1 / 382(0.3)$ & 0/189 (0.0) \\
\hline $100,000-500,000$ & $1 / 124(0.8)$ & $1 / 62(1.6)$ \\
\hline$>500,000$ & $2 / 25(8.0)$ & $1 / 15(6.7)$ \\
\hline \multicolumn{3}{|l|}{$\begin{array}{l}\mathrm{CD} 4^{+} \mathrm{T} \text {-cell count }(\text { cells/ } \\
\mathrm{mm}^{3} \text { ) }\end{array}$} \\
\hline$>200$ & $0 / 462(0.0)$ & $0 / 229(0.0)$ \\
\hline 50 to 200 & $2 / 60(3.3)$ & $2 / 31(6.5)$ \\
\hline$<50$ & $2 / 9(22.2)$ & $0 / 6(0.0)$ \\
\hline
\end{tabular}

*PDVF: nonresponse (did not achieve HIV-1 RNA $<40$ copies per milliliter by week 24) or rebound (HIV-1 RNA $\geq 40$ copies per milliliter after initial response of HIV-1 RNA $<40$ copies per milliliter and confirmed at least 1 week later).

$\dagger$ Resistance testing required blood sample with HIV-1 RNA at least 500 copies per milliliter (threshold of the assay).

\$Time of resistance testing was affected by availability of a sample with sufficient HIV-1 RNA.

Treatment compliance was high overall: $97.2 \%$ of QD recipients and $95.9 \%$ of BID recipients were at least $90 \%$ compliant with study therapy.

\section{Efficacy}

At week 96, HIV-1 RNA $<40$ copies per milliliter was achieved by $81.5 \%(433 / 531)$ of the participants who received raltegravir $1200 \mathrm{mg} \mathrm{QD}$ and by $80.1 \%$ (213/266) of those who received raltegravir $400 \mathrm{mg}$ BID (Fig.2). The treatment difference was $1.4 \%$, with an associated $95 \% \mathrm{CI}$ of -4.4 to 7.3, demonstrating noninferiority of raltegravir $1200 \mathrm{mg}$ QD to raltegravir $400 \mathrm{mg}$ BID. Other virologic outcomes were
TABLE 3. Summary of Clinical Adverse Events, Cumulative Rates Through Week 48 and Week 96

\begin{tabular}{|c|c|c|c|c|}
\hline & \multicolumn{4}{|c|}{ No. (\%) of Participants } \\
\hline & \multicolumn{2}{|c|}{ Weeks 0-48 } & \multicolumn{2}{|c|}{ Weeks 0-96 } \\
\hline & $\begin{array}{c}\text { RALQD* } \\
(\mathbf{N}=\mathbf{5 3 1})\end{array}$ & $\begin{array}{c}\text { RAL BID* } \\
(\mathbf{N}=266)\end{array}$ & $\begin{array}{c}\text { RALQD* } \\
(\mathbf{N}=531)\end{array}$ & $\begin{array}{c}\text { RAL BID* } \\
(\mathbf{N}=\mathbf{2 6 6})\end{array}$ \\
\hline One or more $\mathrm{AE}$ & $439(82.7)$ & $231(86.8)$ & $479(90.2)$ & $248(93.2)$ \\
\hline Drug-related AE & $130(24.5)$ & $68(25.6)$ & $138(26.0)$ & $71(26.7)$ \\
\hline Serious AE & $31(5.8)$ & $25(9.4)$ & $49(9.2)$ & $42(15.8)$ \\
\hline $\begin{array}{l}\text { Drug-related serious } \\
\text { AE }\end{array}$ & $1(0.2)$ & $2(0.8)$ & $1(0.2)$ & $2(0.8)$ \\
\hline $\begin{array}{l}\text { Discontinued study } \\
\text { because of } \mathrm{AE}\end{array}$ & $4(0.8)$ & $6(2.3)$ & $5(0.9)$ & $6(2.3)$ \\
\hline $\begin{array}{l}\text { Because of drug- } \\
\text { related } \mathrm{AE}\end{array}$ & $0(0.0)$ & $2(0.8)$ & $0(0.0)$ & $2(0.8)$ \\
\hline $\begin{array}{l}\text { Because of } \\
\text { serious } \\
\text { AE }\end{array}$ & $3(0.6)$ & $2(0.8)$ & $4(0.8)$ & $2(0.8)$ \\
\hline $\begin{array}{l}\text { Because of drug- } \\
\text { related serious } \\
\mathrm{AE}\end{array}$ & $0(0.0)$ & $0(0.0)$ & $0(0.0)$ & $0(0.0)$ \\
\hline Deaths $\dagger$ & $2(0.4)$ & $1(0.4)$ & $2(0.4)$ & $1(0.4)$ \\
\hline
\end{tabular}

*In combination with FTC/TDF once daily.

†Two deaths in RAL $1200 \mathrm{mg}$ QD arm: immunoblastic lymphoma and TB; 1death in RAL $400 \mathrm{mg}$ BID arm: AIDS (multiple opportunistic infections). No deaths occurred after week 48 .

comparable between the treatment groups: 9.2\% of the QD group and $8.3 \%$ of the BID group had HIV-1 RNA $\geq 40$ copies per milliliter, whereas $9.2 \%$ and $11.7 \%$, respectively, had no virologic data at week 96 (Table 1).

Similar efficacy also was demonstrated between raltegravir QD and raltegravir BID on the supportive endpoint of virologic response defined as HIV-1 RNA $<50$ copies per milliliter $(82.7 \%$ vs $80.8 \%)$. The mean change from baseline in $\mathrm{CD}^{+} \mathrm{T}$-cell count was 262 cells $/ \mathrm{mm}^{3}$ in both treatment groups, with a treatment difference $(95 \% \mathrm{CI})$ of $-0.6(-32.8$ to 31.6$)$.

In the subgroup analyses, raltegravir $1200 \mathrm{mg}$ QD showed durable antiretroviral and immunologic efficacy comparable to that observed with raltegravir $400 \mathrm{mg}$ BID, regardless of prognostic and demographic factors (Fig.3). Participants with high baseline viral load $(>100,000$ copies per milliliter) showed similar robust virologic responses at week 96 in both the QD and BID treatment groups (HIV-1 RNA $<40$ copies per milliliter achieved in $84.7 \%$ and $82.9 \%$, respectively), as well as similar increases in $\mathrm{CD}^{+} \mathrm{T}$-cell counts (297 and 281 cells $/ \mathrm{mm}^{3}$, respectively).

By week 96, a total of 77 participants met the PDVF criteria for nonresponse or rebound, 9.6\% (51/531) of the raltegravir QD group and 9.8\% (26/266) of the raltegravir BID group, with 23 cases (15 QD; 8 BID) occurring after week 48. Most (92.2\%) participants with PDVF were at least $90 \%$ compliant with study therapy. A substantial number of participants who met the PDVF criteria remained on study therapy (at the investigator's discretion, as allowed by the protocol) and achieved HIV-1 RNA < 40 copies per milliliter at week 96: $45.1 \%(23 / 51)$ in the QD group and $57.7 \%(15 / 26)$ in the BID group.

Most participants with PDVF had low-level viremia, and only 25 (17 QD, 8 BID) could be tested for viral drug 
TABLE 4. Laboratory Changes Grade 2 or Higher, Incidence $\geq 1 \%$ in Either Treatment Group, Week 96

\begin{tabular}{|c|c|c|c|}
\hline & RAL 1200 mg QD* & RAL 400 mg BID* & Difference (QD - BID) \\
\hline & $\mathbf{n} / \mathbf{N}(\%)$ & $\mathbf{n} / \mathbf{N}(\%)$ & $\%(95 \% \mathrm{CI})$ \\
\hline \multicolumn{4}{|l|}{ Neutrophils $\left(10^{3} / \mu \mathrm{L}\right)$} \\
\hline Grade $2(0.75-0.999)$ & $8 / 530(1.5)$ & $2 / 265(0.8)$ & $0.8(-1.3$ to 2.3$)$ \\
\hline Grade $3(0.50-0.749)$ & $7 / 530(1.3)$ & $3 / 265(1.1)$ & $0.2(-2.0$ to 1.8$)$ \\
\hline Grades 2-4 combined & $16 / 530(3.0)$ & $5 / 265(1.9)$ & $1.1(-1.5$ to 3.3$)$ \\
\hline \multicolumn{4}{|l|}{ Platelets $\left(10^{3} / \mu \mathrm{L}\right)$} \\
\hline Grade 2 (50-99.999) & 6/529 (1.1) & $1 / 266(0.4)$ & $0.8(-1.0$ to 2.1$)$ \\
\hline \multicolumn{4}{|l|}{ Total bilirubin (mg/dL) } \\
\hline Grade $2(1.6-2.5 \times \mathrm{ULN})$ & $15 / 530(2.8)$ & $4 / 266(1.5)$ & $1.3(-1.2$ to 3.4$)$ \\
\hline \multicolumn{4}{|l|}{ Aspartate aminotransferase (IU/L) } \\
\hline Grade $2(2.6-5.0 \times \mathrm{ULN})$ & $24 / 530(4.5)$ & $7 / 266(2.6)$ & $1.9(-1.1$ to 4.5$)$ \\
\hline Grade $3(5.1-10.0 \times \mathrm{ULN})$ & $11 / 530(2.1)$ & $1 / 266(0.4)$ & $1.7(-0.1$ to 3.4$)$ \\
\hline Grades $2-4$ combined & $38 / 530(7.2)$ & $9 / 266(3.4)$ & $3.8(0.4$ to 6.8$)$ \\
\hline \multicolumn{4}{|l|}{ Alanine aminotransferase (IU/L) } \\
\hline Grade $2(2.6-5.0 \times \mathrm{ULN})$ & $22 / 530(4.2)$ & $4 / 266(1.5)$ & $2.6(0.0$ to 5.0$)$ \\
\hline Grade $3(5.1-10.0 \times$ ULN $)$ & $6 / 530 \dagger(1.1)$ & $1 / 266(0.4)$ & $0.8(-1.0$ to 2.1$)$ \\
\hline Grade $4(>10.0 \times \mathrm{ULN})$ & $6 / 530 \ddagger(1.1)$ & $1 / 266 \S(0.4)$ & $0.8(-1.0$ to 2.1$)$ \\
\hline Grades 2-4 combined & $34 / 530(6.4)$ & $6 / 266(2.3)$ & $4.2(1.1$ to 6.9$)$ \\
\hline \multicolumn{4}{|l|}{ Alkaline phosphatase } \\
\hline Grade $2(2.6-5.0 \times \mathrm{ULN})$ & 6/530 (1.1) & $0 / 266(0.0)$ & $1.1(-0.3$ to 2.4$)$ \\
\hline \multicolumn{4}{|l|}{ Lipase (IU/L) } \\
\hline Grade $2(1.6-3.0 \times \mathrm{ULN})$ & $37 / 530(7.0)$ & $14 / 266(5.3)$ & $1.7(-2.1$ to 5.0$)$ \\
\hline Grade $3(3.1-5.0 \times$ ULN $)$ & $8 / 530(1.5)$ & $2 / 266(0.8)$ & $0.8(-1.3$ to 2.3$)$ \\
\hline Grade $4(>5.0 \times$ ULN $)$ & $9 / 530(1.7)$ & $2 / 266(0.8)$ & $0.9(-1.1$ to 2.6$)$ \\
\hline Grades $2-4$ combined & $54 / 530(10.2)$ & $18 / 266(6.8)$ & $3.4(-0.9$ to 7.2$)$ \\
\hline \multicolumn{4}{|l|}{ Creatine phosphokinase (IU/L) } \\
\hline Grade $2(6.0-9.9 \times \mathrm{ULN})$ & $23 / 530(4.3)$ & $13 / 266(4.9)$ & $-0.5(-4.1$ to 2.4$)$ \\
\hline Grade $3(10.0-19.9 \times$ ULN $)$ & $17 / 530(3.2)$ & $7 / 266(2.6)$ & $0.6(-2.4$ to 2.9$)$ \\
\hline Grade 4 ( $\geq 20.0 \times$ ULN) & $18 / 530(3.4)$ & $5 / 266(1.9)$ & $1.5(-1.2$ to 3.8$)$ \\
\hline Grades $2-4$ combined & $58 / 530(10.9)$ & 25/266 (9.4) & $1.5(-3.2$ to 5.8$)$ \\
\hline
\end{tabular}

*In combination with FTC/TDF once daily.

$\dagger$ One case was associated with acute hepatitis of undetermined etiology.

$\$$ Two cases were associated with acute HCV infection and 1with acute HBV infection.

$\S$ This case was associated with acute HCV infection.

resistance because of the assay threshold of HIV-1 RNA $\geq 500$ copies per milliliter (Table 2 ). Viral resistance to INSTI and nucleoside reverse transcriptase inhibitor (NRTI) occurred in $0.8 \%$ of each treatment group $(4 / 531 \mathrm{QD}, 2 / 266$ BID), and NRTI resistance alone occurred in $0.4 \%$ of each group (2/531 QD; 1/266 BID). The profile of INSTI resistance mutations included integrase $\mathrm{N} 155 \mathrm{H}$, V151I, L74M, E92Q, and I203M. Five of the 6 participants who developed resistance to raltegravir had baseline HIV-1 RNA $>100,000$ copies per milliliter $(3 \mathrm{had}>500,000$ copies per milliliter), and all 6 had baseline $\mathrm{CD}^{+}{ }^{+} \mathrm{T}$-cell counts $<200$ / $\mathrm{mm}^{3}$ ( $\left.2 \mathrm{had}<50 / \mathrm{mm}^{3}\right)$. Self-reported treatment adherence was high in all 6 of these participants (95\%-100\% in the QD group; $91 \%-100 \%$ in the BID group).

\section{Safety}

Rates of clinical adverse events were similar between the treatment groups at week 96 and showed minimal change from week 48 to week 96 in both the treatment groups (Table 3).
Clinical adverse events led to treatment discontinuation by week 96 in $0.9 \%$ of raltegravir QD recipients and $2.3 \%$ of raltegravir BID recipients. Only 1 participant (who was in the QD group) discontinued because of a clinical adverse event (facial bone fracture) after week 48; this event was serious and not related to study therapy. No deaths or drug-related serious adverse events occurred after week 48. One participant in the QD group had an adverse event (autoimmune hepatitis) after week 48, which was considered by the investigator to be associated with immune reconstitution inflammatory syndrome; this event was also considered to be related to study therapy. The frequencies of other drug-related adverse events in the QD group were unchanged between week 48 and week 96.

Drug-related nervous system adverse events occurred in $37(7.0 \%)$ of raltegravir QD recipients and $26(9.8 \%)$ of raltegravir BID recipients. Specific drug-related nervous system adverse events with $>2 \%$ incidence were dizziness $(2.3 \%$ vs $3.4 \%)$ and headache $(3.0 \%$ vs $4.9 \%)$. Drug-related psychiatric adverse events occurred in $21(4.0 \%)$ of the QD group and 12 (4.5\%) of the BID group; specific drug-related 
psychiatric AEs occurred in less than 2\% of the participants in each treatment group.

Laboratory abnormalities above grade 1 by the Division of AIDS criteria were uncommon and occurred at similar rates in the raltegravir QD and BID groups (Table 4) with 1 exception: grade 2 elevations of alanine aminotransferase (ALT) occurred in $4.2 \%$ of the QD group vs $1.5 \%$ of the BID group; however, these elevations were generally transient, not associated with clinical adverse events, and not considered clinically significant by the investigators.

Grade 3 or 4 ALT elevations occurred in $12(2.3 \%)$ participants in the QD group and $2(0.8 \%)$ in the BID group by week 96 ; about half of these events ( 5 and 1 , respectively) occurred after week 48. Most of these events were related to concurrent conditions (hepatitis in 8 participants, hepatocellular injury in 1 , hepatic steatosis in 1 , and isoniazid treatment in 1). The 3 cases with no obvious etiology resolved on study therapy. Grade 3 or 4 elevations in creatine phosphokinase (CPK) occurred in $35(6.6 \%)$ QD recipients and $12(4.5 \%)$ BID recipients by week 96; of these, 19 and 1, respectively, occurred after week 48 . These changes were transient and resolved on therapy in most cases (33 and 11, respectively). Grade 3 or 4 lipase elevations occurred in $17(3.2 \%)$ of the QD group and $4(1.6 \%)$ of the BID group by week 96 ; of these, 4 and 3, respectively, occurred after week 48. Lipase elevations were not associated with clinical symptoms with the exception of 1 QD recipient who experienced moderate pancreatitis that resolved while continuing study therapy.

Two participants (both in the QD group) discontinued therapy because of laboratory changes: increased ALT and aspartate aminotransferase (AST) (grade 3 and 1, respectively) in 1 and increased CPK (grade 4) in the other; both events occurred before week 48 . None of the laboratory events that occurred after week 48 led to treatment discontinuation in either treatment group.

Two participants met the criteria for potential druginduced liver injury (AST or ALT $\geq 3 \times$ ULN [upper limit of the normal range] with bilirubin $\geq 2 \times U L N$ and alkaline phosphatase $<2 \mathrm{xULN}$ ): 1 in the QD group before week 48 and 1 in the BID group after week 48. In both cases, there were alternative explanations for the laboratory findings (hepatitis $\mathrm{B}$ virus flare and acute hepatitis $\mathrm{C}$ virus, respectively).

Among participants with hepatitis coinfection, no drugrelated adverse events, serious adverse events, or discontinuations because of adverse events were reported after week 48 in either treatment group. Two of the 15 coinfected participants in the raltegravir QD group had laboratory adverse events after week 48 (grade 4 elevations of lipase and creatine kinase, respectively), but neither event was considered drug-related. No new reports of AST or ALT elevations above grade 2 occurred after week 48 among coinfected participants in either treatment group.

\section{DISCUSSION}

The final 96-week results of this pivotal phase 3 trial in treatment-naive adults with HIV-1 infection demonstrate the durable and noninferior efficacy of raltegravir $1200 \mathrm{mg}$ QD compared with raltegravir $400 \mathrm{mg}$ BID, each in combination with FTC/TDF. The noninferior efficacy and favorable safety profile of raltegravir $1200 \mathrm{mg}$ QD were first demonstrated at week 48 and have been previously reported. ${ }^{10}$ At week 96, the efficacy of raltegravir $1200 \mathrm{mg}$ QD was again shown to be noninferior to that of raltegravir $400 \mathrm{mg}$ BID, as assessed by the proportion of participants with HIV-1 RNA $<40$ copies per milliliter. Similar results were observed for the supportive virologic endpoint of HIV-1 RNA $<50$ copies per milliliter, and both treatment groups continued to show substantial increases in $\mathrm{CD}^{+} \mathrm{T}$-cell counts (over 260 cells $/ \mathrm{mm}^{3}$ ) through week 96. In addition, raltegravir $1200 \mathrm{mg}$ QD showed comparable efficacy to raltegravir $400 \mathrm{mg}$ BID across all subgroups examined, including those with high baseline viral load. Overall, the efficacy of raltegravir $1200 \mathrm{mg}$ QD in this study is comparable to that of dolutegravir and elvitegravir reported at 96 weeks. ${ }^{13-18}$

PDVF was used to identify participants for drug resistance testing. At week 96, the frequency of PDVF was low and similar between the raltegravir QD and BID groups (9.6\% and $9.8 \%$, respectively). The rate of viral drug resistance also remained low, with only 3 additional reports after week 48: 1 in the QD group and 2 in the BID group. By week $96,0.8 \%$ of each group developed resistance to INSTI and resistance to NRTI. Development of resistance was associated with high baseline viral load and low $\mathrm{CD}^{+}{ }^{+} \mathrm{T}$ cell count in 5 of the 6 cases, but did not seem to be related to poor treatment adherence. In previous studies of raltegravir $400 \mathrm{mg}$ BID in treatment-naive adults, rates of resistance to INSTI ranged from $1 \%$ to $2 \%$ at 96 weeks of follow-up. ${ }^{19,20}$ The specific integrase mutations observed in this study were consistent with those found in the Phase 3 studies of raltegravir BID in treatment-naive and treatmentexperienced adults. ${ }^{20-22}$ Resistance testing was possible in only a small subset of participants with PDVF; additional resistance may have been selected in participants with confirmed viremia but could not be detected because the HIV-1 RNA was below the assay threshold of 500 copies per milliliter.

The favorable safety profile of raltegravir $400 \mathrm{mg}$ BID was established in clinical trials ${ }^{1-4}$ and confirmed by postmarketing experience. ${ }^{23-25}$ At week 96 of the ONCEMRK trial, the QD and BID regimens continued to demonstrate favorable safety and tolerability profiles with small increases in the rates of drug-related adverse events after week 48 $(1.5 \%$ and $1.1 \%$, respectively), no serious drug-related adverse events after week 48 , and only 1 discontinuation because of an adverse event after week 48. The raltegravir $1200 \mathrm{mg}$ QD regimen continued to be well tolerated in participants with chronic hepatitis (B or C) coinfection, an important subpopulation among those with HIV-1 infection.

Treatment-emergent laboratory abnormalities were generally similar for raltegravir $1200 \mathrm{mg}$ QD and raltegravir 400 $\mathrm{mg}$ BID. The incidence of grade 3 or 4 elevations in ALT in the QD group $(2.2 \%)$ was higher than that in the BID group $(0.8 \%)$ but was similar to rates reported in previous clinical trials of raltegravir $400 \mathrm{mg}$ BID: $1.8 \%$ in STARTMRK, ${ }^{20}$ $3.4 \%$ in QDMRK, ${ }^{26} 3 \%$ in NEAT001, ${ }^{27}$ and $2 \%$ in SPRING2. ${ }^{15}$ Similarly, the incidence of grade 3 or 4 elevations in AST 
in the QD group (2.1\%) was higher than that in the BID group $(0.4 \%)$ but was similar to previously reported rates for raltegravir $400 \mathrm{mg}$ BID in STARTMRK $(3.2 \%)^{20}$ and QDMRK $(3.4 \%){ }^{26}$ The incidence of grade 3 or 4 CPK elevations (6.6\% in the QD group and $4.5 \%$ in the BID group) was similar to previously reported rates for raltegravir $400 \mathrm{mg}$ BID in QDMRK $(5.4 \%)^{26}$ and NEAT001 (6\%). ${ }^{27}$ The transient nature of the elevations in cases without alternative etiologies (such as viral hepatitis or hepatotoxic concomitant therapies), the small differences between treatment groups, and the finding that most resolved without discontinuation of study therapy suggest that these laboratory changes do not raise new safety concerns for raltegravir QD.

Because the ONCEMRK trial was double-blind, all participants were required to take multiple pills BID; therefore, the potential for improved adherence with the QD regimen could not be evaluated in this trial. The global distribution of the study sites and the racial diversity of the study population support the generalizability of the study results; however, some groups (women, older patients, and those with hepatitis coinfection) were underrepresented. Raltegravir $400 \mathrm{mg}$ BID has shown favorable efficacy and safety in women, ${ }^{28-30}$ hepatitis $\mathrm{C}$ coinfection, ${ }^{31}$ and older patients $^{25}$; additional experience with raltegravir $1200 \mathrm{mg}$ QD in these populations will help define further the safety and efficacy profile of the new formulation. The conclusions that can be drawn from the subgroup analyses are limited for several reasons: some of the subgroups were small, no adjustment was made for multiple comparisons, and the study was not powered to detect statistically significant effects within these subgroups. ${ }^{32}$ Nevertheless, no apparent trends for differences in efficacy within subpopulations were noted in this study.

In summary, the week 96 results of the ONCEMRK trial show that the efficacy of raltegravir $1200 \mathrm{mg}$ QD, previously demonstrated at week 48 , was maintained through week 96 and was similar to the efficacy of raltegravir $400 \mathrm{mg}$ BID. Development of resistance to raltegravir remained low $(0.8 \%)$ in both treatment groups at week 96 . In addition, the overall safety profile of raltegravir $1200 \mathrm{mg}$ QD continues to be consistent with the well-established safety profile of raltegravir $400 \mathrm{mg}$ BID.

\section{ACKNOWLEDGMENTS}

The authors thank the study participants and their families and caregivers for participating in the ONCEMRK study. The contributions of the investigators and their staff are likewise gratefully recognized, along with the following employees of Merck \& Co., Inc., Kenilworth, NJ: Kim M. Strohmaier for medical writing, Carol Zecca for editorial assistance, and Danielle Mancaruso for graphics support.

\section{REFERENCES}

1. Rockstroh JK, DeJesus E, Lennox JL, et al. Durable efficacy and safety of raltegravir versus efavirenz when combined with tenofovir/emtricitabine in treatment-naive HIV-1-infected patients: final 5-year results from STARTMRK. J Acquir Immune DeficSyndr. 2013;63:77-85.
2. Eron JJ, Cooper DA, Steigbigel RT, et al. Efficacy and safety of raltegravir for treatment of HIV for 5 years in the BENCHMRK studies: final results of two randomised, placebo-controlled trials. Lancet Infect Dis. 2013;13:587-596.

3. Sharma M, Walmsley SL. Raltegravir as antiretroviral therapy in HIV/ AIDS. Expert OpinPharmacother. 2014;15:395-405.

4. Calcagno A, D'Avolio A, Bonora S. Pharmacokinetic and pharmacodynamic evaluation of raltegravir and experience from clinical trials in HIV-positive patients. Expert Opin Drug MetabToxicol. 2015;11:1167-1176.

5. Parienti JJ, Bangsberg DR, Verdon R, et al. Better adherence with once-daily antiretroviral regimens: a meta-analysis. Clin Infect Dis. 2009;48:484-488.

6. Cooper V, Moyle GJ, Fisher M, et al. Beliefs about antiretroviral therapy, treatment adherence and quality of life in a 48-week randomised study of continuation of zidovudine/lamivudine or switch to tenofovir DF/ emtricitabine, each with efavirenz. AIDS Care. 2011;23:705-713.

7. Cooper V, Horne R, Gellaitry G, et al. The impact of once-nightly versus twice-daily dosing and baseline beliefs about HAART on adherence to efavirenz-based HAART over 48 weeks: the NOCTE study. J Acquir Immune DeficSyndr. 2010;53:369-377.

8. Jayaweera D, Dejesus E, Nguyen KL, et al. Virologic suppression, treatment adherence, and improved quality of life on a once-daily efavirenz-based regimen in treatment-Naive HIV-1-infected patients over 96 weeks. HIV Clin Trials. 2009;10:375-384.

9. ISENTRESS HD (raltegravir) Film-Coated Tablets. Kenilworth, NJ: Merck \& Co., Inc. 2017.

10. Cahn P, Kaplan R, Sax PE, et al. Raltegravir $1200 \mathrm{mg}$ once daily versus raltegravir $400 \mathrm{mg}$ twice daily, with tenofovirdisoproxilfumarate and emtricitabine, for previously untreated HIV-1 infection: a randomised, double-blind, parallel-group, phase 3, non-inferiority trial. Lancet HIV. 2017;4:e486-e494.

11. U.S. Department of Health and Human Services, National Institutes of Health, National Institute of Allergy and Infectious Diseases, Division of AIDS. Division of AIDS Table for Grading the Severity of Adult and Pediatric Adverse Events, Version 1.0; 2009. Available at: http://rsc.techres.com/docs/default-source/safety/table_for_grading_severity_of_adult_ pediatric adverse events.pdf. Accessed October 7, 2013.

12. Miettinen O, Nurminen M. Comparative analysis of two rates. Stat Med. $1985 ; 4: 213-226$.

13. Molina JM, Clotet B, van Lunzen J, et al. Once-daily dolutegravir versus darunavir plus ritonavir for treatment-naive adults with HIV-1 infection (FLAMINGO): 96 week results from a randomised, open-label, phase $3 \mathrm{~b}$ study. Lancet HIV. 2015;2:e127-36.

14. Walmsley S, Baumgarten A, Berenguer J, et al. Brief report: dolutegravir plus abacavir/lamivudine for the treatment of HIV-1 infection in antiretroviral therapy-naive patients: week 96 and week 144 results from the SINGLE randomized clinical trial. J Acquir Immune DeficSyndr. 2015;70:515-519.

15. Raffi F, Jaeger H, Quiros-Roldan E, et al. Once-daily dolutegravir versus twice-daily raltegravir in antiretroviral-naive adults with HIV-1 infection (SPRING-2 study): 96 week results from a randomised, double-blind, non-inferiority trial. Lancet Infect Dis. 2013;13:927-935.

16. Wohl D, Oka S, Clumeck N, et al. Brief report: arandomized, doubleblind comparison of tenofovir alafenamide versus tenofovir disoproxil fumarate, each coformulated with elvitegravir, cobicistat, and emtricitabine for initial HIV-1 treatment: week 96 results. J Acquir Immune DeficSyndr. 2016;72:58-64.

17. Zolopa A, Sax PE, DeJesus E, et al. A randomized double-blind comparison of coformulate delvitegravir/cobicistat/emtricitabine/tenofovir disoproxil fumarate versus efavirenz/emtricitabine/tenofovir disoproxil fumarate for initial treatment of HIV-1 infection: analysis of week 96 results. J Acquir Immune DeficSyndr. 2013;63:96-100.

18. Rockstroh JK, DeJesus E, Henry K, et al. A randomized, double-blind comparison of coformulate delvitegravir/cobicistat/emtricitabine/tenofovir DF vs ritonavir-boosted atazanavir plus coformulate demtricitabine and tenofovir DF for initial treatment of HIV-1 infection: analysis of week 96 results. J Acquir Immune DeficSyndr. 2013;62:483-486.

19. Lennox JL, Landovitz RJ, Ribaudo HJ, et al. Efficacy and tolerability of 3 nonnucleoside reverse transcriptase inhibitor-sparing antiretroviral regimens for treatment-naive volunteers infected with HIV-1: a randomized, controlled equivalence trial. Ann Intern Med. 2014;161:461-471.

20. Lennox JL, Dejesus E, Berger DS, et al. Raltegravir versus efavirenz regimens in treatment-naive HIV-1-infected patients: 96-week efficacy, 
durability, subgroup, safety, and metabolic analyses. $J$ Acquir Immune DeficSyndr. 2010;55:39-48.

21. Cooper DA, Steigbigel RT, Gatell JM, et al. Subgroup and resistance analyses of raltegravir for resistant HIV-1 infection. $N$ Engl J Med. 2008; 359:355-365.

22. Steigbigel RT, Cooper DA, Teppler H, et al. Long-term efficacy and safety of Raltegravir combined with optimized background therapy in treatment-experienced patients with drug-resistant HIV infection: week 96 results of the BENCHMRK 1 and 2 Phase III trials. Clin Infect Dis. 2010;50:605-612.

23. Elzi L, Erb S, Furrer $\mathrm{H}$, et al. Adverse events of raltegravir and dolutegravir. AIDS.2017;31:1853-1858.

24. van Halsema $\mathrm{C}$, Whitfield $\mathrm{T}$, Lin N, et al. Five years' real-life experience with raltegravir in a large HIV centre. Int J STD AIDS. 2016;27:387-393.

25. Naumann U, Moll A, Schleehauf D, et al. Similar efficacy and tolerability of raltegravir-based antiretroviral therapy in HIV-infected patients, irrespective of age group, burden of comorbidities and concomitant medication: real-life analysis of the German 'WIP' cohort. Int $J$ STD AIDS. 2017;28:893-901.

26. Eron JJ, Rockstroh JK, Reynes J, et al. Raltegravir once daily or twice daily in previously untreated patients with HIV-1: a randomised, activecontrolled, phase 3 non-inferiority trial. Lancet Infect Dis. 2011;11:907915.

27. Raffi F, Babiker AG, Richert L, et al. Ritonavir-boosted darunavir combined with raltegravir or tenofovir-emtricitabine in antiretroviralnaive adults infected with HIV-1: 96 week results from the NEAT001/ ANRS143 randomized non-inferiority trial. Lancet. 2014;384:19421951.

28. Maliakkal A, Walmsley S, Tseng A. Critical review: review of the efficacy, safety, and pharmacokinetics of raltegravir in pregnancy. $J$ Acquir Immune DeficSyndr. 2016;72:153-161.

29. Squires KE, Bekker LG, Eron JJ, et al. Safety, tolerability, and efficacy of raltegravir in a diverse cohort of HIV-infected patients: 48-week results from the REALMRKstudy. AIDS ResHum Retroviruses. 2013;29: 859-870.

30. Squires K, Bekker LG, Katlama C, et al. Influence of sex/gender and race on responses to raltegravir combined with tenofovir-emtricitabine in treatment-naive human immunodeficiency Virus-1 infected patients: pooled analyses of the STARTMRK and QDMRK studies. Open Forum Infect Dis. 2017;4:ofw047.

31. Taramasso L, Cenderello G, Riccardi N, et al. Role of Raltegravir in patients co-infected with HIV and HCV in the era of direct antiviral agents. New Microbiol. 2017;40:227-233.
32. Wang R, Lagakos SW, Ware JH, et al. Statistics in medicine-reporting of subgroup analyses in clinical trials. N Engl J Med. 2007;357:21892194.

\section{APPENDIX 1. The ONCEMRK Study Group}

\section{ONCEMRK Primary Investigators (by country):}

Argentina: P. E. Cahn, I.Cassetti, M.Losso; Australia: M.T. Bloch, N. Roth, J. McMahon, R. J. Moore, D. Smith; Belgium: N.Clumeck, L. Vanderkerckhove, B.Vandercam, M.Moutschen; Canada: J.Baril, B. Conway, F.Smaill, G. H. R. Smith, A.Rachlis, S. L.Walmsley; Chile: C. Perez, M. Wolff, M. F. Lasso, C. E.Chahin; Colombia: J. D. Velez, O.Sussmann; France: J.Reynes, C.Katlama, Y.Yazdanpanah, S. Ferret, J. Durant, C. Duvivier, I.Poizot-Martin, F.Ajana; Germany: J. K.Rockstroh, G.Faetkanheuer, S.Esser, H. Jaeger, O.Degen, M. Bickel, J.Bogner, K.Arasteh, H.Hartl, A. Stoehr; Guatemala: E. M. Rojas, E.Arathoon, L. D. Gonzalez, C. R. Mejia; Israel: E.Shahar, D. Turner, I. Levy, Z.Sthoeger, H.Elinav; Italy: A.Gori, A. D'ArminioMonforte, G. Di Perri, A.Lazzarin, G.Rizzardini, A.Antinori, B. M.Celesia, F.Maggiolo; Malaysia: T. S. Chow, C. K. C. Lee, R.Iskandar Shah Raja Azwa, M. Mustafa; Peru: M.Oyanguren, R. A. Castillo, L.Hercilla; Phillippines: C.Echiverri; Portugal: F.Maltez, J. G.Saraiva da Cunha, I. Neves, E.Teofilo, R.Serrao; Russia: F.Nagimova, I.Khaertynova, E.OrlovaMorozova, E.Voronin, V.Sotnikov, A. A.Yakovlev, N. G.Zakharova, O. A. Tsybakova; South Africa: M. E.Botes, L.Mohapi, R. Kaplan, M. S.Rassool; Spain: J. R.Arribas, J. M.Gatell, E.Negredo, E. Ortega, J.Troya, J.Berenguer, K.Aguirrebengoa, A.Antela; Switzerland: A.Calmy, M.Cavassini, A. Rauch, M.Stoeckle; Taiwan: W.-H. Sheng, H. -H. Lin, H. -C. Tsai; Thailand: D. Changpradub, A.Avihingsanon, S.Kiertiburanakul, W.R.; United Kingdom: M. R. Nelson, A. Clarke, A.Ustianowski, A. Winston, M. A. Johnson; United States: D. M.Asmuth, J. Cade, J. E. Gallant, P. J.Ruane, P. N. Kumar, A. E. Luque, L. Panther, K. T.Tashima, D. Ward, D. S. Berger, C. A. Dietz, C. Fichtenbaum, S. Gupta, K. M.Mullane, R. M. Novak, D. E. Sweet, G. E. Crofoot, D. P.Hagins, S. T. Lewis, C. K. McDonald, E.DeJesus, L. Sloan, D. J.Prelutsky, J. C.Rondon, S.Henn, A. J.Scarsella, J. O. Morales-Ramirez, L. Santiago, C. D.Zorrilla, M. S.Saag, C. -B. Hsiao. 